\section{Questión}

Periodismo / Comunicación ISSN 1669-6581
- Av. $44 \mathrm{~N}^{\circ} 676,1^{\circ}$ piso

CP 1900 - La Plata - Argentina

www.perio.unlp.edu.ar/question

Lecciones de El Eternauta en tiempos de pandemia

Tomás Bergero Trpin

DOI: https://doi.org/10.24215/16696581e297

\title{
Lecciones de El Eternauta en tiempos de pandemia
}

\section{Lessons from El Eternauta in times of pandemic}

Tomás Bergero Trpin / tomasbergero@gmail.com Periodista especializado en la producción de proyectos digitales. Licenciado en Comunicación Social por la Universidad Nacional de La Plata y maestrando en Comunicación Digital Interactiva por la Universidad Nacional de Rosario.

"Dentro del universo de El Eternauta". Así nos sentimos muchos devotos de la obra de Oesterheld y Solano López cuando el silencio se apoderó de las calles y comenzamos a usar tapabocas para protegernos de esa amenaza que podría estar flotando en el aire. Si releemos las páginas de la popular historieta de fines de los años cincuenta no sólo encontraremos aspectos similares al contexto actual, sino también algunas enseñanzas que podemos aprovechar para enfrentar el "incidente" que intentamos problematizar en este nuevo suplemento de la Revista Cuestión/Question, con el rigor de los tiempos que corren.

"Éramos robinsones que, en lugar de quedar atrapados en una isla, estábamos aislados en nuestra propia casa. No nos rodeaba el océano pero sí la muerte" (Oesterheld y Solano López, 2012: 20).

Si de analogías hablamos, lo primero que debemos mencionar es el problema de fondo, el "nudo" de estas historias. En resumidas cuentas, la humanidad se enfrenta a una amenaza externa, invisible y letal. En uno y otro plano (el de la realidad y el de la ficción) hay algo, una suerte de entidad que no podemos ver en su esencia misma pero que percibimos a través de sus diferentes manifestaciones. De un lado tenemos un elemento que a ésta altura forma parte del imaginario popular: la nevada mortal que cubrió Buenos Aires una fría noche de 1963. Por 
otra parte, una serie de síntomas similares a los de una neumonía, que con el correr de los días se replican en distintos pacientes a una velocidad inusitada.

Ahora bien, quien haya leído la historieta sabe que esa nevada aparentemente radioactiva, al igual que los Cascarudos, los temibles Gurbos y hasta los Manos que los manipulan, eran en verdad armas y fuerzas de choque de un enemigo invisible: los Ellos, una especie de colonizadores galácticos que carecen de representación física en las viñetas dibujadas por Solano López. Aunque la diferencia parezca abismal, ocurre algo similar en este plano. De un tiempo a esta parte nos enfrentamos con los síntomas producidos por esa entidad invisible a nuestros ojos que es el SARS-CoV-2, es decir, el virus que causa la enfermedad COVID-19. Si bien sabemos que hay varios laboratorios trabajando a contrarreloj en el desarrollo de una vacuna, los profesionales de la salud tienen claro que por el momento sólo nos queda aislarnos y tratar los síntomas de los enfermos para resistir el avance del virus, al igual que Juan Salvo y la resistencia terrestre combatieron la maquinaria de aquellos seres informes.

Me había propuesto no utilizar metáforas bélicas, pero las referencias se imponen en el decurso del artículo. Esto se debe a que la historieta versa justamente sobre una invasión alienígena con epicentro en Buenos Aires; y al uso recurrente de estos términos por parte de políticos y medios de comunicación. La enfermedad es presentada como una amenaza por la propia Organización Mundial de la Salud y los gobiernos la identifican como un enemigo al cual hay que combatir. Esto nos lleva a otro punto interesante: el enemigo no sólo es invisible sino que es externo. Después del pico de casos en la ciudad china de Wuhan, el mundo comprobó que el SARS-CoV-2 viajaba en avión. Causalmente, el país que en la actualidad registra la mayor tasa de contagio del mundo (Estados Unidos) es uno de los que menos ha reducido su tráfico aéreo. Otros países, como Argentina, que rápidamente cerraron las fronteras para evitar el ingreso y la circulación local del virus, han hecho descender notablemente el porcentaje de casos importados y mantienen la tasa de contagio en niveles estables.

A lo largo de las extensas coberturas mediáticas de la pandemia de enfermedad por coronavirus COVID-19 hemos visto que las personas adoptan diversas actitudes frente a situaciones límite como la que nos toca vivir. Así, a través de la televisión, la radio, la prensa y las redes sociales digitales conocimos a los acaparadores, a los irresponsables que violan el Aislamiento Social Preventivo Obligatorio, a los solidarios que ayudan a sus vecinos, a los especuladores, a las y los médicos que ponen en riesgo su vida, entre un sinnúmero de 
personajes que también tienen su contraparte en las viñetas de El Eternauta. Hagamos un ejercicio para transformar la personalidad de algunos de los personajes principales en estereotipos como los que mencionamos anteriormente:

Los Polsky: pierden la cabeza frente a situaciones extremas y toman decisiones de manera apresurada sin medir las consecuencias.

Los Favalli: analizan la realidad de manera metódica y cuentan con un "cerebro práctico" para resolver problemas complejos.

Los Salvo: mantienen la calma y la objetividad frente al horror. Su principal objetivo es proteger a su familia y son capaces de cualquier cosa con tal de hacerlo.

Los Herbert: son temerosos y desconfían de sus pares.

Además de estos personajes, hay otros a los que deberíamos prestarle especial atención porque, al fin y al cabo, son introducidos en la historieta para hablarnos sobre la condición humana. Me refiero a los "lobos", a esos anónimos que aprovechan las catástrofes para sembrar miedo y beneficiarse:

"Pronto imperaría a nuestro alrededor la ley de la jungla, la ley del más fuerte, el matar o morir propio de la selva. Por eso debíamos prepararnos para afrontar cualquier peligro" (Oesterheld y Solano López, 2012: 25)

La trama, los personajes, la estética y las metáforas de El Eternauta se prestan a seguir estableciendo analogías entre la ficción y la realidad. Sin embargo, aprovecharemos este espacio para centraremos en aquellas lecciones o enseñanzas que nos deja este clásico literario.

Solidaridad: si hay algo que distingue a El Eternauta de los cómics anglosajones es el hecho de que el protagonista no es un superhéroe que utiliza sus poderes para salvar a la humanidad, sino más bien un antihéroe, un hombre que se une con sus pares para hacer frente a la amenaza extraterrestre. El mismo Héctor Germán Oesterheld plasmó su interpretación en el prólogo a la primera edición de 1957: "El héroe verdadero de El Eternauta es un héroe colectivo, un grupo humano. Refleja así, aunque sin intención previa, mi sentir íntimo. El único héroe válido es el héroe 'en grupo', nunca el héroe individual, el héroe sólo" (Oesterheld y Solano López, 1994: 1). De esta manera, la obra nos enseña que la salida al problema que enfrentamos no es individual, sino colectiva, y que todos tenemos algo que aportar. 
Resistencia: la obra y, paradójicamente, la vida del propio Oesterheld está signada por la resistencia. "¿Qué queda por hacer cuando es imposible avanzar e inviable retroceder?" (Oesterheld y Solano López, 2012: 6) se pregunta Fernando Ariel García en el prólogo a la edición vintage de 2012: resistir contra el invasor y contra el ejercicio abusivo del poder. Así lo hicieron Juan Salvo y Oesterheld hasta el último momento, y así lo tiene que hacer (nuevamente) la humanidad en este momento.

Miedo: los seres humanoides conocidos como Manos, que en un principio parecen ser quienes controlan la ofensiva extraterrestre, son manipulados por los Ellos a través de una "glándula del terror" implantada en sus cuerpos que es capaz de segregarles un veneno mortal en caso de verse sometidos a un desbalance emocional como el que podría provocar el deseo de rebelarse contra sus opresores. El miedo, que en nuestro plano es infundido por gobiernos y medios de comunicación, es una forma de control social que cuestiona de manera directa la solidaridad y la responsabilidad social necesaria en los tiempos que corren. Como afirma Monika Arredondo (2020), el miedo "corrompe las relaciones y los sentimientos, y deja al individuo apresado entre sus miedos y presto a ser sometido". Una vez que se lo inocula “produce desconfianza y 'conflicto' con ese 'otro' al que se le atribuye la culpa de lo ocurrido y de lo que pueda acontecer, y crea la necesidad de protegerse de él", derivando en un sentimiento de odio.

Ciencia: de todos los personajes de El Eternauta mi preferido es Favalli. No sólo por el rol que cumple en la trama, sino por lo que representa: la ciencia o, al menos, el razonamiento deductivo. Este profesor universitario de física sobresale por su inteligencia y su capacidad para resolver problemas, aspectos que lo llevan a ser el encargado de definir las estrategias de ataque y defensa de la resistencia. En cada una de sus apariciones, Favalli analiza la realidad "desde una perspectiva impersonal" dirá Juan Salvo y formula explicaciones (hipótesis) que suelen verificarse rápidamente en los hechos. Es el personaje que continuamente devela el misterio de la trama, que nos explica qué es lo que está sucediendo. La cuarta enseñanza, entonces, es escuchar a los Favalli de nuestro mundo, a esa comunidad científica que cuenta con los conocimientos, métodos y recursos para enfrentar el avance del coronavirus COVID-19. Tiempo: la transformación del humilde Juan Salvo en el Eternauta ocurre tras un accidente que envía al protagonista hacia una dimensión fuera del espacio-tiempo terrestre. A partir de allí, el "viajero de la eternidad" navega a través del azar de los continum (sic) en busca de su familia, 
hasta llegar al punto donde comienza la historieta. El Eternauta, vale aclarar, no controla su destino, es un peregrino de los tiempos que sólo quiere regresar a su hogar. En esta historieta y otras obras de su autoría, como Mort Cinder, Oesterheld parece recordarnos que somos esclavos del tiempo. Durante la cuarentena ese commoditie de la modernidad se volvió completamente líquido: ¿quién no experimentó el solapamiento entre los momentos de trabajo, ocio, descanso, socialización e información? Nuestro desafío más grande hoy no es llegar a casa, sino gobernar y administrar ese tiempo que se escurre entre las manos.

Ser solidarios, resistir las adversidades, no dejar que el miedo corrompa las relaciones sociales, basar nuestras decisiones en evidencia científica y aprender a gobernar el tiempo son sólo algunas de las lecciones que nos deja El Eternauta. Lo curioso es que estas premisas no se refieren a escenarios futuros, como podríamos esperar de una obra de ciencia ficción, sino a la condición del propio ser humano. Tal como lo señalan los compiladores del libro H. G. Oesterheld. Más allá de Gelo, Mariano Chinelli y Martín Hadis:

"La vigencia que conserva hoy la obra de Oesterheld es sorprendente; la clave de esto reside acaso en que su tema subyacente es la naturaleza humana, y pocas cosas hay en el mundo tan imperecederas como ésta" (2014: 15).

\section{Bibliografía}

Arredondo, M. (12 de marzo de 2020). La construcción del miedo. Página/12. Recuperado de https://www.pagina12.com.ar/252431-la-construccion-del-miedo [Consulta realizada el 22/04/2020].

Canaparo, C. (2007). Mobilis in mobili: ciencia y tecnología en El Eternauta. Revista Iberoamericana, Vol. LXXIII, Núm. 221, pp. 871-886.

Chinelli, M. y Hadis, M. [Comp.] (2014). H. G. Oesterheld. Más allá de Gelo. Planeta: Ciudad Autónoma de Buenos Aires.

Oesterheld, H. G. y Solano López, F. (1994). El Eternauta. Ediciones Record: Buenos Aires.

Oesterheld, H. G. y Solano López, F. (2012). El Eternauta: Edición Vintage. Doedytores: Buenos Aires. 